\title{
The Chemistry of $\mathrm{CH}_{2} \mathrm{I}_{2}$ on MoAl Alloy Thin Films Formed on Dehydroxylated Alumina: Insight into Methylene Insertion Reactions
}

\author{
Y. Wang, F. Gao, and W. T. Tysoe* \\ Department of Chemistry and Biochemistry, and Laboratory for Surface Studies, University of \\ Wisconsin-Milwaukee, Milwaukee, Wisconsin 53211
}

Received: April 20, 2005; In Final Form: June 22, 2005

\begin{abstract}
The chemistry of diiodomethane is explored in ultrahigh vacuum on a MoAl alloy film grown on planar, dehydroxylated alumina by reaction with molybdenum hexacarbonyl. The majority of the diiodomethane forms methylene species below $\sim 250 \mathrm{~K}$, although a small proportion forms $\mathrm{CH}_{2} \mathrm{I}_{(\text {ads })}$, which hydrogenates to form iodomethane. The majority $(\sim 90 \%)$ of the adsorbed methylene species thermally decomposes to carbon and hydrogen. The remainder undergoes several reactions, including partial hydrogenation to form adsorbed methyl species or total hydrogenation to form methane. The methyl species can couple forming ethane or undergo methylene insertion reactions to form alkyl species up to $\mathrm{C}_{4}$. These form alkenes via a $\beta$-hydride elimination reaction. This chemistry is relatively unique, only having been found previously for $\mathrm{Ni}(110)$ surfaces. No such chemistry is found on $\mathrm{Ni}(100)$ and $\mathrm{Ni}(111)$.
\end{abstract}

\section{Introduction}

$\mathrm{Mo}(\mathrm{CO})_{6}$ has been extensively used to deposit molybdenum on oxides to generate catalysts and catalyst precursors. ${ }^{1-12}$ Such a procedure has been applied in ultrahigh vacuum to generate model catalysts supported on planar alumina thin films, where surface-sensitive spectroscopic probes can be used to investigate the surfaces and catalytic reactions. ${ }^{13-16}$ Our recent studies have shown that reacting $\mathrm{Mo}(\mathrm{CO})_{6}$ with aluminum ${ }^{17}$ and alumina ${ }^{18}$ thin films at $500 \mathrm{~K}$ and above forms molybdenum carbide incorporating a small amount of oxygen. Efforts have been made to perform hydrocarbon conversion reactions on these surfaces, and it is found that these surfaces are rather inert. Such inertness has been found recently by Chen et al. ${ }^{19}$ by adsorbing $\mathrm{O}_{2}$ on molybdenum carbide and has been rationalized by site blocking rather than by electronic modification effects. Annealing these films to temperatures higher than $1200 \mathrm{~K}$ causes $\mathrm{CO}$ desorption through alumina reduction by the carbidic carbon and results in molybdenum-aluminum alloy formation. ${ }^{17,18}$

It has been shown previously that reaction of low exposures of $\mathrm{Mo}(\mathrm{CO})_{6}$ with alumina films above $500 \mathrm{~K}$ results in the formation of nanoparticles on the surface, while higher exposures (of $\sim 5000 \mathrm{~L}$ of $\mathrm{Mo}(\mathrm{CO})_{6}$ ) lead to a thin film that completely covers the substrate. ${ }^{18}$ The chemistry of hydrogen and $\mathrm{CO}$ on MoAl nanoparticles compared with thin films has been investigated to explore particle size effects in these systems. $^{20}$

In the following, the surface chemistry of diiodomethane is investigated on the MoAl alloy film. Such a strategy has been extensively used to examine the surface chemistry of hydrocarbons on surfaces since organic iodides tend to decompose by scission of the $\mathrm{C}-\mathrm{I}$ bonds at relatively low temperatures to deposit hydrocarbon fragments, along with chemisorbed iodine. ${ }^{21,22}$ The chemistry of iodomethane has recently been explored on the alloy surface ${ }^{23}$ where, in addition to hydrogen and methane desorption, the formation of higher hydrocarbons,

* To whom correspondence should be addressed. Phone: (414) 2295222; fax: (414) 229-5036; e-mail: wtt@uwm.edu. ethylene, ethane, and propylene, was also found. These products are suggested to form through methylene insertion into alkylmetal bonds followed by $\beta$-hydride or reductive elimination to form oligomers. In this case, methylene species are formed by partial dehydrogenation of adsorbed methyl species. The chemistry of methylene species is explored directly in the following by studying diiodomethane on the MoAl alloy surface, where methylene species are directly formed by $\mathrm{C}-\mathrm{I}$ bond cleavage.

The MoAl alloy film formation and characterization has been extensively described. ${ }^{18}$ Briefly, it is formed by adsorbing 5000 $\mathrm{L}$ of $\mathrm{Mo}(\mathrm{CO})_{6}$ onto a dehydroxylated alumina film grown on a Mo(100) substrate held at $700 \mathrm{~K}$, so that a molybdenum carbide film incorporating a small amount of oxygen is formed. The sample is subsequently annealed to $1500 \mathrm{~K}$ to generate a MoAl alloy. Alloy formation is confirmed by X-ray photoelectron and Auger spectroscopies.

The surface chemistry of diiodomethane has been investigated previously on several transition-metal surfaces including $\mathrm{Cu},{ }^{24,25}$ Ag, ${ }^{26-28} \mathrm{Mo},{ }^{29,30} \mathrm{Pd},{ }^{31,32} \mathrm{Pt},{ }^{33} \mathrm{Rh},{ }^{34,35} \mathrm{Ru},{ }^{36}$ and $\mathrm{Ni} .{ }^{37,38}$ Studies have also been performed on Al surfaces. ${ }^{39-41}$ It has been found that coupling to form ethylene, decomposition to carbon and hydrogen, and hydrogenation to methane are the main reaction pathways on transition metals. One exception appears to be $\mathrm{Ni}$ $(110)^{38}$ where up to $10 \%$ of alkanes and alkenes, up to $\mathrm{C}_{4}$, are formed. The surface chemistry on aluminum is quite different from that on the transition metals. It has been found that methylene coupling reactions occur at $\sim 170 \mathrm{~K}$ resulting in ethylene desorption, while neither methane nor hydrogen desorption is observed. ${ }^{39}$ On the other hand, $\mathrm{AlI}_{3}, \mathrm{AlHI}_{2}, \mathrm{AlI}$, and $\mathrm{CH}_{3} \mathrm{Al}(\mathrm{H}) \mathrm{I}$ desorb at temperatures higher than $400 \mathrm{~K}$, and the surface chemistry is highly dependent on the $\mathrm{CH}_{2} \mathrm{I}_{2}$ exposure. ${ }^{40}$

\section{Experimental Section}

Temperature-programmed desorption (TPD) data were collected in an ultrahigh vacuum chamber operating at a base 
pressure of $8 \times 10^{-11}$ Torr that has been described in detail elsewhere ${ }^{13,17,18}$ where desorbing species were detected using a Dycor quadrupole mass spectrometer placed in line of sight of the sample. This chamber was also equipped with a doublepass cylindrical mirror analyzer for collecting Auger spectra.

$\mathrm{X}$-ray photoelectron spectra (XPS) were collected in another chamber operating at a base pressure of $2 \times 10^{-10}$ Torr, which was equipped with Specs X-ray source and double-pass cylindrical mirror analyzer. Spectra were typically collected with a $\mathrm{Mg} \mathrm{K} \alpha \mathrm{X}$-ray power of $250 \mathrm{~W}$ and a pass energy of $50 \mathrm{eV}$. The deposited film was sufficiently thin that no charging effects were noted, and the binding energies were calibrated using the Mo $3 \mathrm{~d}_{5 / 2}$ feature (at $227.4 \mathrm{eV}$ binding energy) as a standard.

Temperature-programmed desorption spectra were collected at a heating rate of 10 or $15 \mathrm{~K} / \mathrm{s}$. Temperature-dependent XP and Auger spectra were collected by heating the sample to the indicated temperature for $5 \mathrm{~s}$, allowing the sample to cool to $150 \mathrm{~K}$, following which the spectrum was recorded.

The Mo(100) substrate (1-cm diameter, 0.2-mm thick) was cleaned using a standard procedure, which consisted of argon ion bombardment $\left(2 \mathrm{kV}, 1 \mu \mathrm{A} / \mathrm{cm}^{2}\right)$, and any residual contaminants were removed by briefly heating to $2000 \mathrm{~K}$ in vacuo. The resulting Auger spectrum showed no contaminants. Aluminum was deposited onto Mo(100) from a small heated alumina tube, which was enclosed in a stainless steel shroud to minimize contamination of other parts of the system. ${ }^{42}$

Molybdenum hexacarbonyl (Aldrich, 99\%), diiodomethane, and $\mathrm{d}_{2}$-diiodomethane (Aldrich, $99 \%$ ) were transferred to glass vials, were connected to the gas-handling line of the chamber, and were purified by repeated freeze-pump-thaw cycles, followed by distillation, and their purities were monitored using mass spectroscopy. These were dosed onto the surface via a capillary doser to minimize background contamination. The exposures in Langmuirs ( $1 \mathrm{~L}=1 \times 10^{-6}$ Torr) are corrected using an enhancement factor determined using temperatureprogrammed desorption (see ref 13 for a more detailed description of this procedure). $\mathrm{H}_{2}$ and $\mathrm{D}_{2}$ (Matheson, $\geq 99.5 \%$ ) are used without further purification.

\section{Results}

Figure 1displays the Auger spectra of the MoAl alloy film (formed by exposing $5000 \mathrm{~L} \mathrm{Mo}(\mathrm{CO})_{6}$ to dehydroxylated alumina at $700 \mathrm{~K}$ and heating to $1500 \mathrm{~K}^{18}$ ) exposed to various amount of $\mathrm{CH}_{2} \mathrm{I}_{2}$ at $150 \mathrm{~K}$ and subsequently annealed to 750 K. The carbon KLL Auger signal at $\sim 270 \mathrm{eV}$ kinetic energy following $\mathrm{CH}_{2} \mathrm{I}_{2}$ adsorption and annealing suggests that a portion of adsorbed $\mathrm{CH}_{2} \mathrm{I}_{2}$ undergoes complete decomposition. The low intensity of the carbon signal does not allow the nature of the deposited carbon (whether it is graphitic or carbidic) to be identified from the line shape. It is found that the intensity of the $\mathrm{Al}^{0}$ signal at $\sim 66 \mathrm{eV}$ decreases with increasing $\mathrm{CH}_{2} \mathrm{I}_{2}$ exposure up to $5 \mathrm{~L}$ and stays constant at higher exposures. This strongly suggests that some metallic aluminum is oxidized by iodine. The feature at $\sim 520 \mathrm{eV}$ for the alloy film alone indicates that there is a small amount of oxygen initially present in the alloy film. The iodine Auger signal appears at approximately the same energy as oxygen ${ }^{43}$ and the growth in the $\sim 520 \mathrm{eV}$ signal with increasing diiodomethane exposure indicates that it has dissociated to deposit carbon and iodine on the surface.

To explore the dissociation of diiodomethane and the subsequent surface chemistry, XP spectra were collected following adsorption of $5 \mathrm{~L}$ of $\mathrm{CH}_{2} \mathrm{I}_{2}$ on the alloy surface and then annealing to various temperatures, and the results are displayed in Figure 2where each spectrum was taken after the

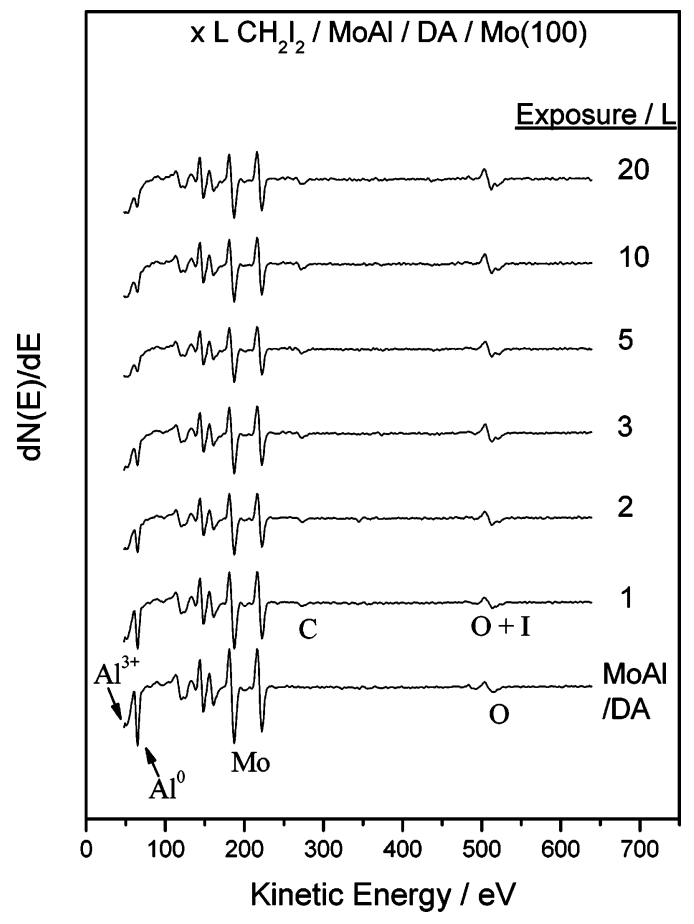

Figure 1. A series of Auger spectra plotted as a function of diiodomethane exposure, where exposures are marked adjacent to the corresponding spectrum, collected following diiodomethane adsorption on a MoAl alloy film at $150 \mathrm{~K}$ and annealing to $750 \mathrm{~K}$. The spectra were collected after allowing the sample to cool to $150 \mathrm{~K}$.

sample is cooled to $\sim 150 \mathrm{~K}$. Shown in Figure $2 \mathrm{a}$ is the $\mathrm{C} 1 \mathrm{~s}$ signal where the low signal intensity is due to the low photoionization cross section. It is found that the $\mathrm{C} 1 \mathrm{~s}$ binding energy is at $284.8 \mathrm{eV}$ at 150 and $200 \mathrm{~K}$. The signal intensity does not decrease on heating to $200 \mathrm{~K}$, suggesting no apparent $\mathrm{CH}_{2} \mathrm{I}_{2}$ desorption at this temperature. The binding energy shifts to $283.4 \mathrm{eV}$ at $250 \mathrm{~K}$ together with a drastic intensity decrease, indicating both desorption and dissociation occurs within this temperature range. The binding energy shifts to $282.7 \mathrm{eV}$ at $400 \mathrm{~K}$ and to $282.5 \mathrm{eV}$ at $500 \mathrm{~K}$ and remains constant at higher temperatures. All carbon is removed from the surface by 1500 $\mathrm{K}$. Figure $2 \mathrm{~b}$ displays the corresponding I $3 \mathrm{~d}$ region. Following $\mathrm{CH}_{2} \mathrm{I}_{2}$ adsorption at $150 \mathrm{~K}$, an $\mathrm{I} 3 \mathrm{~d}_{5 / 2}$ binding energy of 620.0 $\mathrm{eV}$ is found. No chemical shift or intensity decrease is observed at $200 \mathrm{~K}$, in accord with the $\mathrm{C}$ 1s spectra. The binding energy decreases to $619.2 \mathrm{eV}$ together with apparent intensity decrease at $250 \mathrm{~K}$. The binding energy shifts slowly on heating to higher temperatures yielding a value of $619.5 \mathrm{eV}$ at $1100 \mathrm{~K}$. The I $3 \mathrm{~d}_{5 / 2}$ intensity starts to decrease at $900 \mathrm{~K}$ and, by $1200 \mathrm{~K}$, the surface is depleted of iodine.

The resulting gas-phase products are monitored using temperature-programmed desorption (TPD) collected using a heating rate of $10 \mathrm{~K} / \mathrm{s}$. Figure 3a displays 63 amu $\left(\mathrm{I}^{2+}\right)$ desorption profiles as a function of $\mathrm{CH}_{2} \mathrm{I}_{2}$ exposure. This $\mathrm{m} / \mathrm{e}$ ratio is selected since the singly ionized fragment is out of the range $(1-100 \mathrm{amu})$ of the mass spectrometer. This mass represents molecular $\mathrm{CH}_{2} \mathrm{I}_{2}$ desorption at low exposures. As will be shown below, $\mathrm{CH}_{3} \mathrm{I}$ forms at high $\mathrm{CH}_{2} \mathrm{I}_{2}$ exposures and also contributes to the amu 63 signal. At low $\mathrm{CH}_{2} \mathrm{I}_{2}$ exposures $(\leq 2 \mathrm{~L}$, Figure $3 a)$, no molecular desorption occurs, suggesting complete $\mathrm{C}-\mathrm{I}$ bond cleavage. At exposures of $3 \mathrm{~L}$ and above, two desorption states appear concurrently with desorption peak temperatures of $\sim 217$ and $\sim 250 \mathrm{~K}$, respectively. The high-temperature state saturates at an exposure of $\sim 10 \mathrm{~L}$, while the low-temperature state grows indefinitely with exposure so that these are assigned to monolayer and multilayer desorption, respectively. Multilayer 
(a)

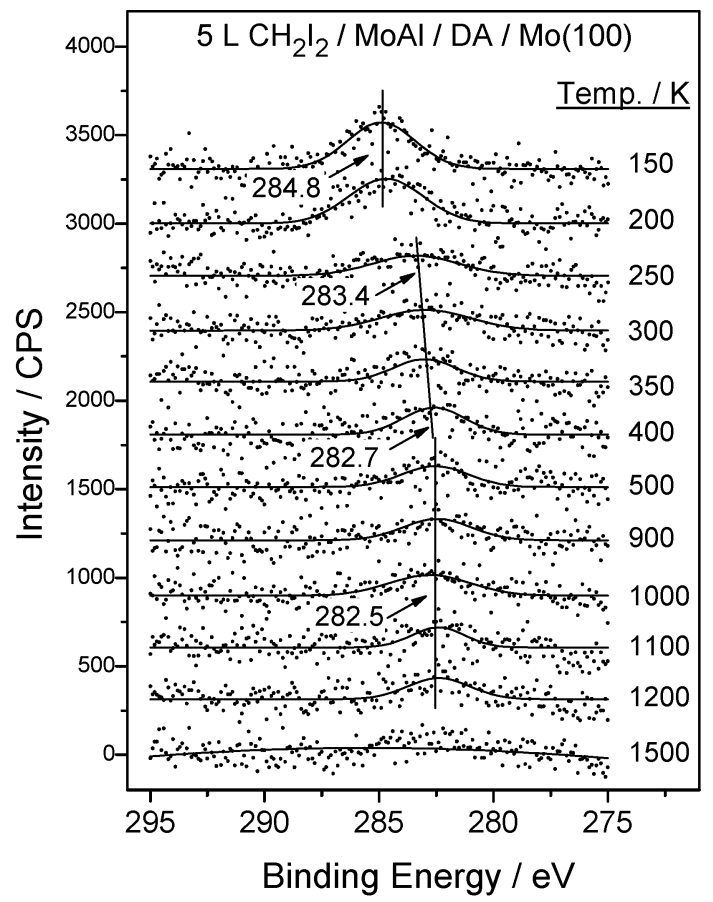

(b)

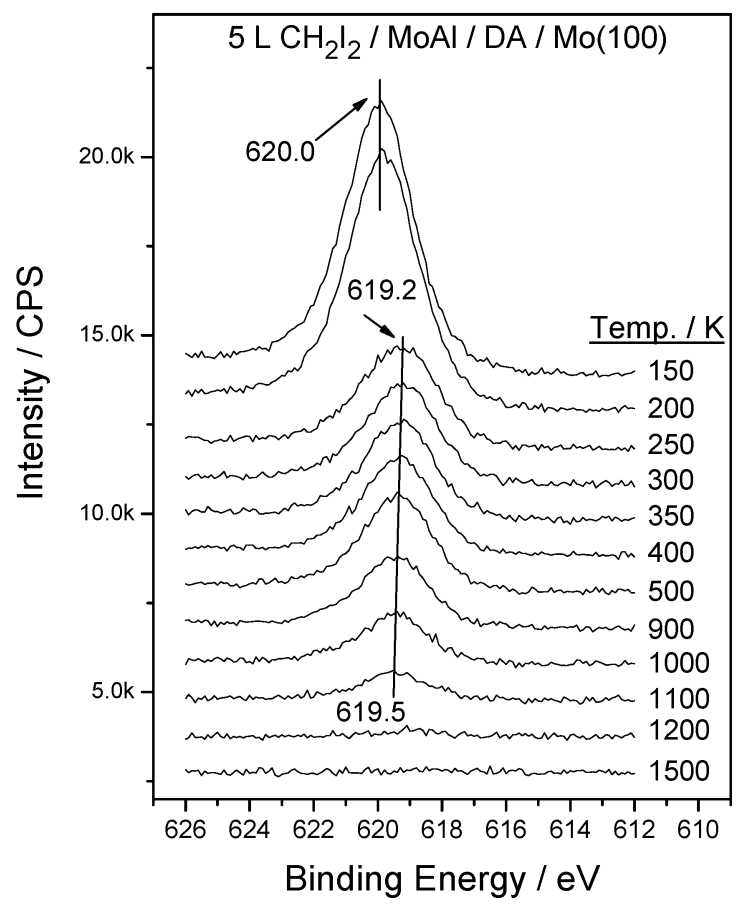

Figure 2. Narrow scan X-ray photoelectron spectra of (a) $\mathrm{C} 1 \mathrm{~s}$ and (b) I $3 \mathrm{~d}$ regions collected following the adsorption of $5 \mathrm{~L}$ of diiodomethane on a MoAl alloy film at $150 \mathrm{~K}$ and heating to various temperatures, where annealing temperatures are marked adjacent to the corresponding spectrum. The spectra were collected after allowing the sample to cool to $150 \mathrm{~K}$.

desorption commences prior to saturation of the monolayer, and the feature at $\sim 180 \mathrm{~K}$ at the highest $\mathrm{CH}_{2} \mathrm{I}_{2}$ exposure $(10 \mathrm{~L})$ is due to some desorption from the sample holder.

Figure $3 b$ presents the amu 71 profiles $\left(\mathrm{CH}_{3} \mathrm{I}^{2+}\right)$ as a function of $\mathrm{CH}_{2} \mathrm{I}_{2}$ exposure. Zaera ${ }^{38}$ has pointed out that $71 \mathrm{amu}$ is due exclusively to $\mathrm{CH}_{3} \mathrm{I}$. This indicates that a portion of $\mathrm{CH}_{2} \mathrm{I}_{2}$ undergoes $\mathrm{C}-\mathrm{I}$ bond cleavage and hydrogen addition to form methyl iodide between 200 and $300 \mathrm{~K}$. This reaction has also has been found on $\mathrm{Ni}(110) .^{38}$

Figure $3 \mathrm{c}$ presents the 2 amu desorption profiles. Several desorption states are evident, where the sharp feature at $\sim 220$
$\mathrm{K}$ at high $\mathrm{CH}_{2} \mathrm{I}_{2}$ exposures is due to fragmentation of the parent molecule in the mass spectrometer ionizer and that centered at $\sim 400 \mathrm{~K}$ at low $\mathrm{CH}_{2} \mathrm{I}_{2}$ exposures is due to hydrogen adsorption from the background, verified by carrying out a blank experiment. The desorption state at $\sim 350 \mathrm{~K}$, which appears as a shoulder at low diiodomethane exposures and shifts to higher temperatures with increasing $\mathrm{CH}_{2} \mathrm{I}_{2}$ exposure, is assigned to the thermal decomposition of adsorbed $\mathrm{CH}_{x}$ species.

Figure $3 \mathrm{~d}$ displays the $16\left(\mathrm{CH}_{4}\right)$ amu signals where the state at $\sim 220 \mathrm{~K}$ at high $\mathrm{CH}_{2} \mathrm{I}_{2}$ exposures is due to fragmentation of the parent molecule. It is observed that even at the lowest $\mathrm{CH}_{2} \mathrm{I}_{2}$ exposure $(0.5 \mathrm{~L})$, methane desorption is apparent at $\sim 330 \mathrm{~K}$. Methane desorption starts at temperatures as low as $200 \mathrm{~K}$ and indicates that a portion of $\mathrm{CH}_{2} \mathrm{I}_{2}$ has dissociated at this temperature. Clearly, methane forms via a stepwise hydrogenation of adsorbed methylene species and a clearer picture will be given below using isotope (deuterium) labeling experiments.

The formation of higher-molecular-weight products is explored in the spectra shown in Figure 4. Shown in the lefthand figure for a $\mathrm{CH}_{2} \mathrm{I}_{2}$ exposure of $1 \mathrm{~L}$, significant intensity is found at 26 and $27 \mathrm{amu}$ in features centered at $\sim 300 \mathrm{~K}$, suggesting ethylene desorption. Some ethane (30 amu) desorbs at slightly lower temperatures. Propylene desorption is also observed at $\sim 300 \mathrm{~K}$ from the 41 amu signal, but no $\mathrm{C}_{4}$ hydrocarbons are found to desorb. A similar chemistry is found at higher $\mathrm{CH}_{2} \mathrm{I}_{2}$ exposures but with some differences. First, some butene ( $56 \mathrm{amu}$ ) desorption is found at $\sim 300 \mathrm{~K}$, and second, an additional ethane ( $30 \mathrm{amu}$ ) desorption state appears at $\sim 210$ $\mathrm{K}$, which becomes evident at a $\mathrm{CH}_{2} \mathrm{I}_{2}$ exposure of $5 \mathrm{~L}$. Especially at $\mathrm{CH}_{2} \mathrm{I}_{2}$ exposures of 3 and $5 \mathrm{~L}$, the 26, 27, and 30 amu profiles all have high-temperature tails extending up to $600 \mathrm{~K}$, suggesting desorption of some $C_{2}$ species at high temperatures. The desorption profiles of 26 and 27 amu signals are slightly different at higher temperatures suggesting aluminumcontaining species may also desorb since $\mathrm{Al}^{+}$has an m/e value of 27. The nature of theses species will be discussed below together with isotope labeling experiments. The olefin desorption temperatures are exposure independent. Finally, no water was found to desorb from the surface.

The fate of the carbon and iodine adsorbed onto the surface after product desorption (Figures 3 and 4) is explored in Figure 5 by carrying out TPD experiments at a heating rate of $15 \mathrm{~K} / \mathrm{s}$ following iodomethane adsorption and after annealing to $\sim 750$ $\mathrm{K}$, where Figure 5a presents the CO (28 amu) desorption profiles, and Figure $5 \mathrm{~b}$ presents the iodine $\left(63 \mathrm{amu}, \mathrm{I}^{2+}\right)$ spectra. It is found that $\mathrm{CO}$ desorbs at $\sim 1196 \mathrm{~K}$ at the smallest $\mathrm{CH}_{2} \mathrm{I}_{2}$ exposure and increases slightly to higher temperatures with increasing $\mathrm{CH}_{2} \mathrm{I}_{2}$ exposures. It has been demonstrated previously that this is due to the reaction between deposited carbon and the alumina substrate. ${ }^{18}$ The desorption peak area is plotted as a function of $\mathrm{CH}_{2} \mathrm{I}_{2}$ exposure as an inset in Figure 5a. The desorption yield increases almost linearly from 0.5 to $4 \mathrm{~L}$ and reaches a maximum at $4 \mathrm{~L}$ and then decreases slightly at an exposure of $5 \mathrm{~L}$. Figure $5 \mathrm{~b}$ shows that iodine desorbs between 800 and $1150 \mathrm{~K}$ and that the integrated desorption peak area versus iodomethane exposure is plotted as an inset showing that the iodine coverage increases rapidly at low $\mathrm{CH}_{2} \mathrm{I}_{2}$ exposures and slows down thereafter.

To better understand the surface chemistry presented above, experiments were also performed using $\mathrm{CD}_{2} \mathrm{I}_{2}$. Figure 6 presents temperature-programmed desorption profiles as a function of $\mathrm{CD}_{2} \mathrm{I}_{2}$ exposure, where amu $63\left(\mathrm{I}^{2+}\right)$ and $72\left(\mathrm{CHD}_{2} \mathrm{I}^{2+}\right.$ and 
(a)

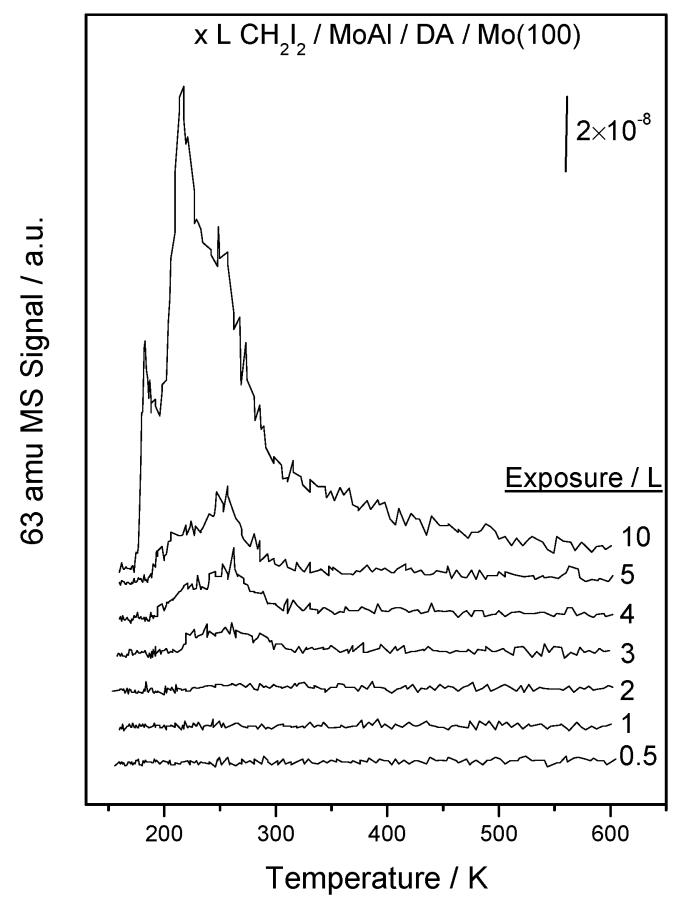

(c)

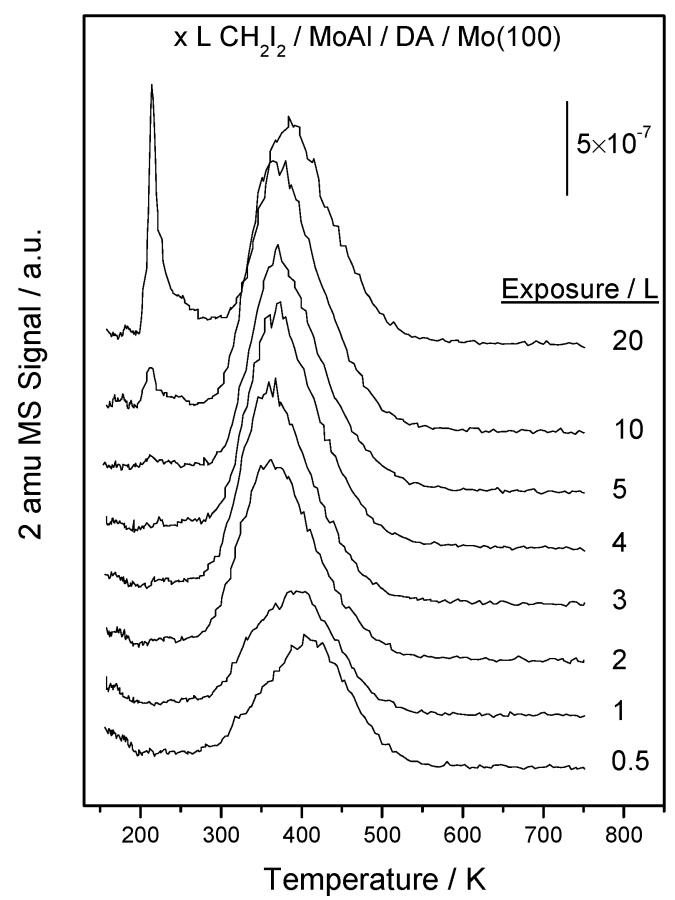

(b)

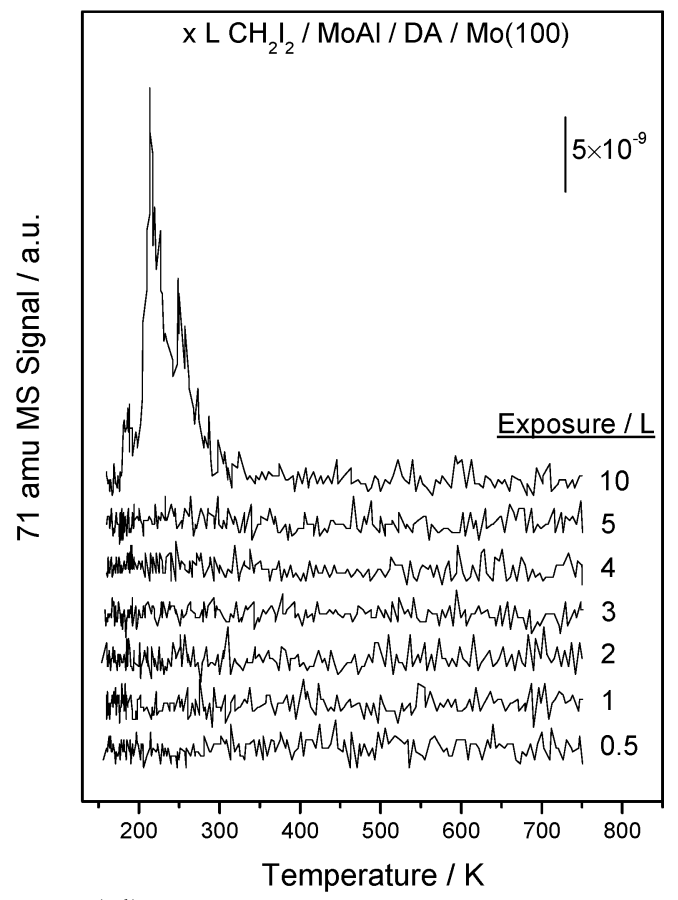

(d)

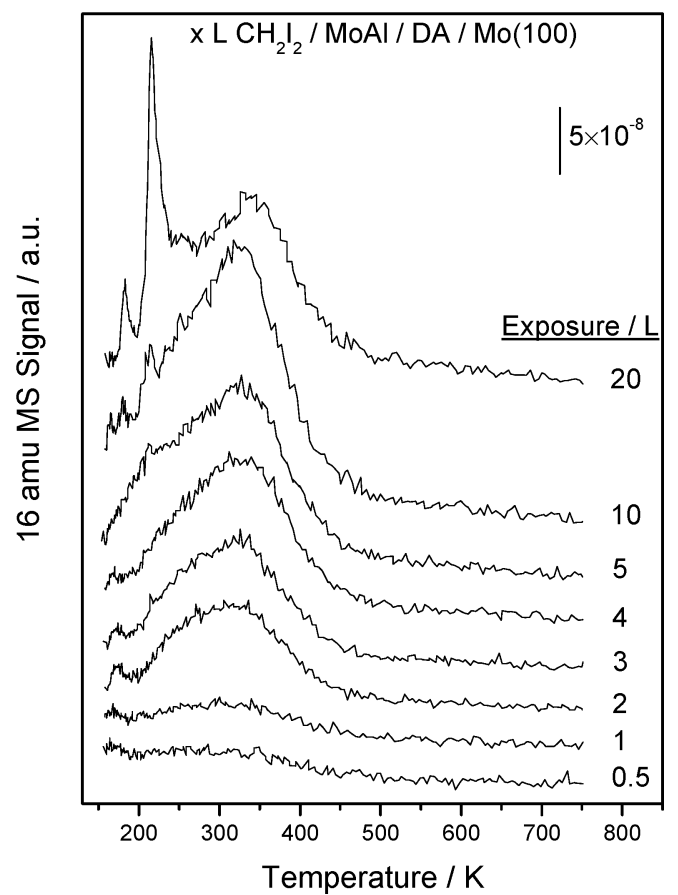

Figure 3. (a) $63\left(\mathrm{I}^{2+}\right)$, (b) $71\left(\mathrm{CH}_{3} \mathrm{I}^{2+}\right)$, (c) $2\left(\mathrm{H}_{2}\right)$, and (d) $16\left(\mathrm{CH}_{4}\right)$ amu temperature-programmed desorption spectra of diiodomethane adsorbed on a MoAl film at $150 \mathrm{~K}$ collected using a heating rate of $10 \mathrm{~K} / \mathrm{s}$, as a function of $\mathrm{CH}_{2} \mathrm{I}_{2}$ exposure. Diiodomethane exposures are marked adjacent to the corresponding spectrum.

$\mathrm{CD}_{3} \mathrm{I}^{2+}$ ) are displayed in Figure 6a and b, respectively. Signals at $73 \mathrm{amu}$ (not shown) mimic those at $72 \mathrm{amu}$, only with smaller intensities. These desorption profiles are similar to those plotted in Figure 3 for $\mathrm{CH}_{2} \mathrm{I}_{2}$. However, $\mathrm{CD}_{2} \mathrm{I}_{2}$ appears to be less reactive compared to $\mathrm{CH}_{2} \mathrm{I}_{2}$ : molecular desorption is observed at $\mathrm{CH}_{2} \mathrm{I}_{2}$ exposures of $3 \mathrm{~L}$ and above, while for $\mathrm{CD}_{2} \mathrm{I}_{2}$, molecular desorption is detectable at an exposure of $2 \mathrm{~L}$. In this case, saturation of the overlayer (evidence by the feature at $\sim 250 \mathrm{~K}$ ) is more evident than in the data of Figure 3a. Again, $\mathrm{CHD}_{2} \mathrm{I}$
$\left(\mathrm{CD}_{3} \mathrm{I}\right)$ formation is observed following monolayer saturation, identical to that found in Figure $3 \mathrm{~b}$.

Figure 7a plots the corresponding $2\left(\mathrm{H}_{2}\right), 3(\mathrm{HD})$, and $4\left(\mathrm{D}_{2}\right)$ amu desorption profiles as a function of $\mathrm{CD}_{2} \mathrm{I}_{2}$ exposure. Apparently $\mathrm{H}_{2}$ originates from background contamination, while deuterium comes from the dissociation of adsorbed $\mathrm{CD}_{2} \mathrm{I}_{2}$. The $\mathrm{H}_{2}$ desorption peak area decreases with increasing $\mathrm{CD}_{2} \mathrm{I}_{2}$ exposure and the $\mathrm{D}_{2}$ desorption peak area increases up to an exposure of $5 \mathrm{~L}$ and saturates thereafter, consistent with the 


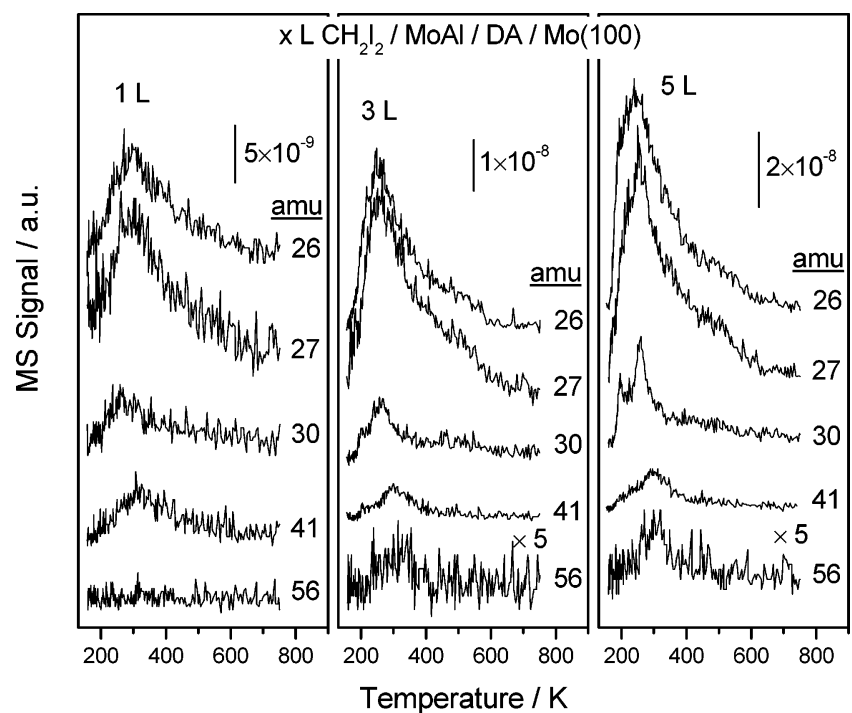

Figure 4. (a) 26, 27, 30, 41, and 56 amu temperature-programmed desorption spectra of diiodomethane adsorbed on a MoAl film at 150 $\mathrm{K}$ collected using a heating rate of $10 \mathrm{~K} / \mathrm{s}$, at $\mathrm{CH}_{2} \mathrm{I}_{2}$ exposures of 1,3 , and $5 \mathrm{~L}$.

spectra shown in Figure 6 . The $\sim 210 \mathrm{~K}$ state at $3 \mathrm{amu}$ at high $\mathrm{CD}_{2} \mathrm{I}_{2}$ exposures is likely due to fragmentation of reactively formed $\mathrm{CHD}_{2} \mathrm{I}$.

Figure $7 \mathrm{~b}$ displays the corresponding $18\left(\mathrm{CH}_{2} \mathrm{D}_{2}\right), 19\left(\mathrm{CHD}_{3}\right)$, and $20\left(\mathrm{CD}_{4}\right)$ amu desorption profiles. Both $\mathrm{CHD}_{3}$ and $\mathrm{CD}_{4}$ have $18 \mathrm{amu}$ fragments, but this contribution is negligible at low $\mathrm{CD}_{2} \mathrm{I}_{2}$ exposures. The desorption profiles of $\mathrm{CH}_{2} \mathrm{D}_{2}$ are broader than those of $\mathrm{CHD}_{3}$ and $\mathrm{CD}_{4}$ and extensive desorption occurs below $300 \mathrm{~K}$, while for the latter two molecules, the desorption peak maxima are higher. These suggest that, although $\mathrm{CD}_{2}$ species dissociate at $\sim 200 \mathrm{~K}$ (indicated by the lowtemperature $\mathrm{CD}_{4}$ desorption), extensive dissociation only occurs above $300 \mathrm{~K}$.

Higher-molecular-weight hydrocarbon desorption was also followed after $\mathrm{CD}_{2} \mathrm{I}_{2}$ adsorption, and similar chemistry is found as for $\mathrm{CH}_{2} \mathrm{I}_{2}$. For the purpose of simplicity, only the ethylene desorption profiles are plotted (Figure 8). Both $\mathrm{C}_{2} \mathrm{D}_{4}$ and $\mathrm{C}_{2}$ $\mathrm{HD}_{3}$ desorb from the surface at $\sim 280 \mathrm{~K}$ at $\mathrm{CD}_{2} \mathrm{I}_{2}$ exposures of $2 \mathrm{~L}$ and above. The desorption temperature of both molecules does not vary with $\mathrm{CD}_{2} \mathrm{I}_{2}$ exposure. The same behavior has been found for $\mathrm{C}_{2} \mathrm{H}_{4}$ desorption shown in Figure 4, suggesting these are not formed by methylene coupling. In cases where methylene coupling does occur, for instance, on $\mathrm{Cu}(100)$, ethylene desorption temperature decreases with increasing diiodomethane exposures $^{44}$ as expected for a second-order reaction.

The data shown in Figure $7 \mathrm{~b}$ imply that hydrogen appears to be more reactive than deuterium since $\mathrm{CH}_{2} \mathrm{D}_{2}$ desorbs at a lower temperature than $\mathrm{CHD}_{3}$ and $\mathrm{CD}_{4}$. However, this effect may be due to a slower $\mathrm{C}-\mathrm{D}$ bond cleavage. To address this question, TPD experiments are performed on $\mathrm{H}_{2^{-}}\left(\mathrm{D}_{2^{-}}\right)$saturated surfaces (20 L exposure), and the results are plotted in Figure 9. Higher methane yields are found in these cases compared with Figures $3 \mathrm{~d}$ and $7 \mathrm{~b}$, confirming methane formation occurs via hydrogenation of methylene species by surface hydrogen. These data indicate that $\mathrm{H}$ is more reactive than $\mathrm{D}$ in terms of methane formation, especially for reaction between $\mathrm{CD}_{2} \mathrm{I}_{2}$ and $\mathrm{D}_{2}$ where the yield of $\mathrm{CH}_{2} \mathrm{D}_{2}$ (amu 18) is comparable to that of $\mathrm{CD}_{4}$ (amu 20). It is also clear that $\mathrm{CH}_{2} \mathrm{I}_{2}$ dissociates more easily than $\mathrm{CD}_{2} \mathrm{I}_{2}$, indicated by the much lower methane yield when $\mathrm{CH}_{2} \mathrm{I}_{2}$ is adsorbed on deuterium-covered surface. One last point to
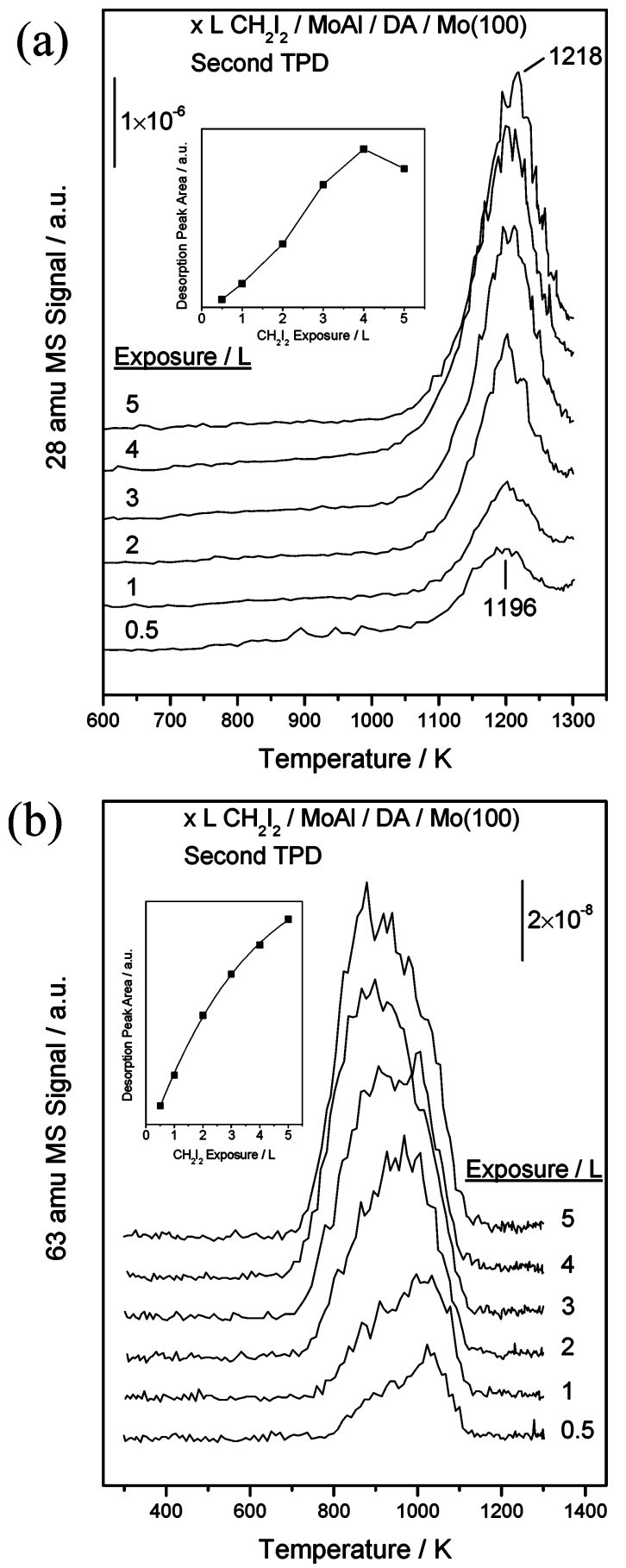

Figure 5. (a) 28 (CO) and (b) $63\left(\mathrm{I}^{2+}\right)$ amu temperature-programmed desorption spectra of diiodomethane adsorbed on the MoAl film at 150 $\mathrm{K}$ and then annealed to $750 \mathrm{~K}$, collected using a heating rate of 15 $\mathrm{K} / \mathrm{s}$, as a function of $\mathrm{CH}_{2} \mathrm{I}_{2}$ exposure. Diiodomethane exposures are marked adjacent to the corresponding spectrum. Shown as insets in both spectra are the integrated desorption yields as a function of diiodomethane exposure.

mention is that even in the $\mathrm{CH}_{2} \mathrm{I}_{2}+\mathrm{D}_{2}$ case, detectable amounts of $\mathrm{CHD}_{3}$ (amu 19) and $\mathrm{CD}_{4}$ (amu 20) are found.

\section{Discussion}

4.1. Diiodomethane Dissociation. The Auger spectra shown in Figure 1 provide a broad picture of the surface chemistry following $\mathrm{CH}_{2} \mathrm{I}_{2}$ adsorption at $150 \mathrm{~K}$ and annealing to $750 \mathrm{~K}$. Evidently, a portion of $\mathrm{CH}_{2} \mathrm{I}_{2}$ undergoes complete dissociation to deposit carbon and iodine on the surface. It appears that iodine 

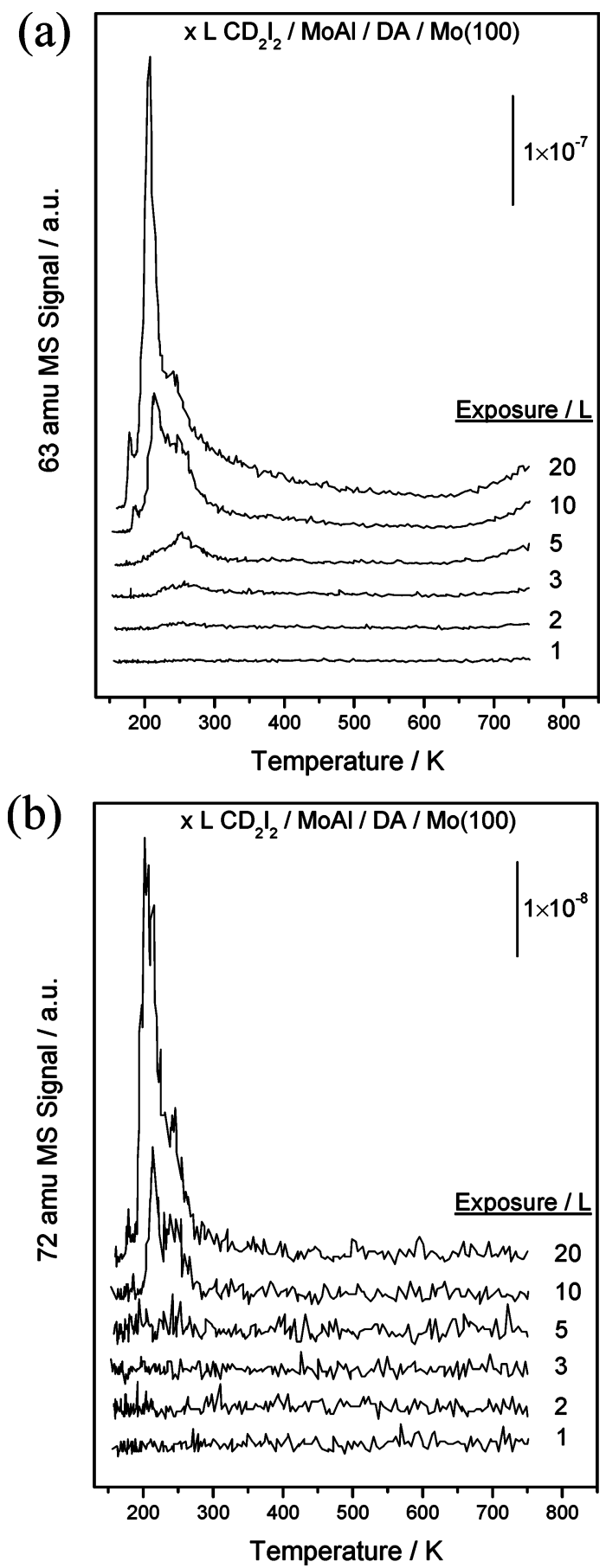

Figure 6. (a) $63\left(\mathrm{I}^{2+}\right)$ and (b) $72\left(\mathrm{CHD}_{2} \mathrm{I}^{2+}\right.$ and $\left.\mathrm{CD}_{3} \mathrm{I}^{2+}\right)$ amu temperature-programmed desorption spectra of diiodomethane adsorbed on a MoAl film at $150 \mathrm{~K}$ collected using a heating rate of $10 \mathrm{~K} / \mathrm{s}$, as a function of $\mathrm{CD}_{2} \mathrm{I}_{2}$ exposure. $\mathrm{CD}_{2} \mathrm{I}_{2}$ exposures are marked adjacent to the corresponding spectrum.

adsorbs preferentially on aluminum, indicated by the $\mathrm{Al}^{0}$ (66 $\mathrm{eV}$ ) signal decrease with increasing $\mathrm{CH}_{2} \mathrm{I}_{2}$ exposure up to $5 \mathrm{~L}$. For $\mathrm{CH}_{2} \mathrm{I}_{2}$ exposures of 10 and $20 \mathrm{~L}$, no further $\mathrm{Al}^{0}$ signal intensity decrease is seen suggesting monolayer saturation, and this is confirmed by TPD results (Figure 3a).

XPS and TPD results provide more information on $\mathrm{CH}_{2} \mathrm{I}_{2}$ dissociation. No previous XPS studies have been carried out for diiodomethane dissociation on molybdenum surfaces. ${ }^{22}$ XPS measurements have been performed for $\mathrm{CH}_{2} \mathrm{I}_{2}$ adsorbed on aluminum ${ }^{39}$ where an I $3 \mathrm{~d}_{5 / 2}$ binding energy of $621.3 \mathrm{eV}$ is found following adsorption at $90 \mathrm{~K}$, which decreases to $619.6 \mathrm{eV}$ on heating to $300 \mathrm{~K}$, while the $\mathrm{C} 1 \mathrm{~s}$ binding energy is $286.2 \mathrm{eV}$ at (a)

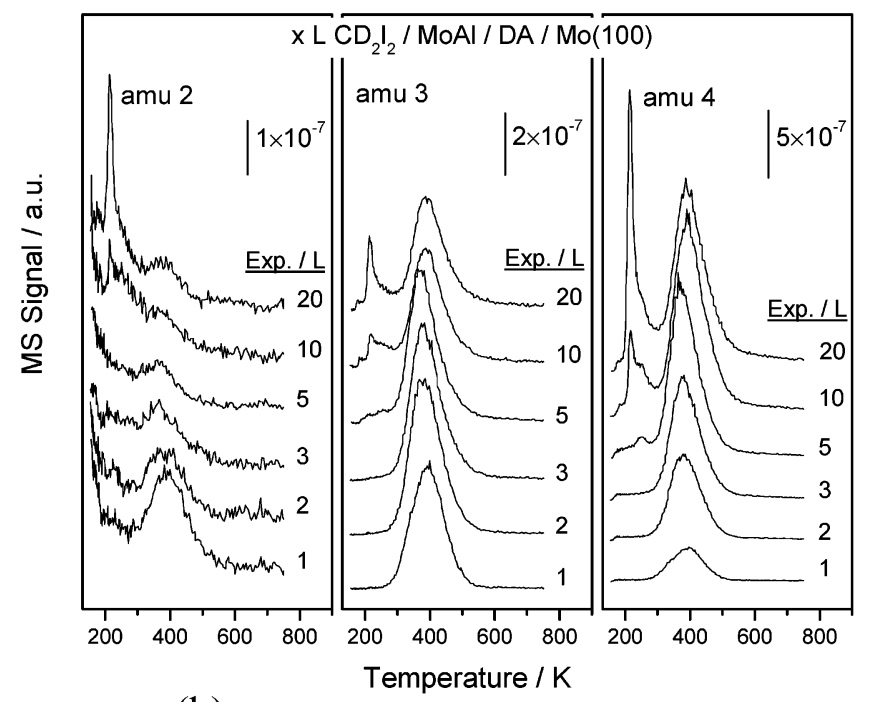

(b)

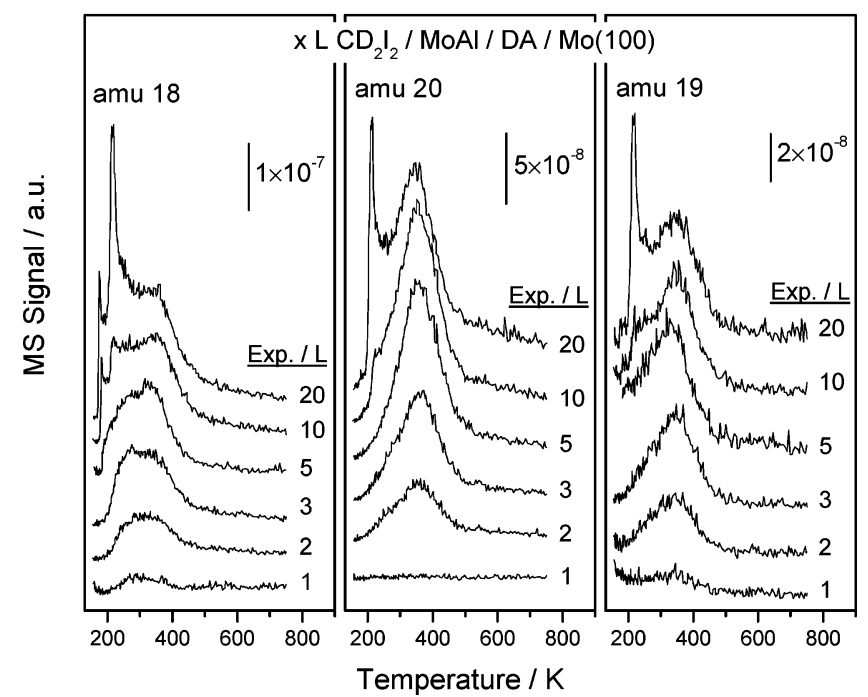

Figure 7. (a) $2\left(\mathrm{H}_{2}\right), 3(\mathrm{HD})$, and $4\left(\mathrm{D}_{2}\right)$ amu and (b) $18\left(\mathrm{CH}_{2} \mathrm{D}_{2}\right), 19$ $\left(\mathrm{CHD}_{3}\right)$, and $20\left(\mathrm{CD}_{4}\right)$ amu temperature-programmed desorption spectra of $\mathrm{CD}_{2} \mathrm{I}_{2}$ adsorbed on MoAl film at $150 \mathrm{~K}$ collected using a heating rate of $10 \mathrm{~K} / \mathrm{s}$, as a function of $\mathrm{CD}_{2} \mathrm{I}_{2}$ exposure.

$90 \mathrm{~K}$ and decreases to $283.5 \mathrm{eV}$ at $300 \mathrm{~K}$. As shown in Figure 2, following $\mathrm{CH}_{2} \mathrm{I}_{2}$ adsorption at $150 \mathrm{~K}$ and annealing to 200 $\mathrm{K}$, both the $\mathrm{C} 1 \mathrm{~s}$ and $\mathrm{I} 3 \mathrm{~d}_{5 / 2}$ signals do not decrease noticeably in intensity or shift in binding energy, indicating that $\mathrm{CH}_{2} \mathrm{I}_{2}$ does not dissociate in this temperature range. This is in accord with the TPD spectra displayed in Figure 9 where methane desorption becomes evident above $200 \mathrm{~K}$. On heating to 250 $\mathrm{K}$, both the $\mathrm{C} 1 \mathrm{~s}$ and $\mathrm{I} 3 \mathrm{~d}_{5 / 2}$ signals attenuate and undergo a binding energy shift, indicating extensive $\mathrm{CH}_{2} \mathrm{I}_{2}$ dissociation, where the $\mathrm{C} 1 \mathrm{~s}$ binding of $283.4 \mathrm{eV}$ at $250 \mathrm{~K}$ implies some $\mathrm{CH}_{x}$ formation. ${ }^{38}$ However, it is difficult to determine exactly what species are present on the surface on the basis only of XPS, partly because of the low $\mathrm{C} 1 \mathrm{~s}$ photoionization cross section. On heating to $400 \mathrm{~K}$, the $\mathrm{C} 1 \mathrm{~s}$ binding energy shifts slowly to $282.7 \mathrm{eV}$ and undergoes an additional shift to 282.5 $\mathrm{eV}$ at $500 \mathrm{~K}$ and above. These values suggest the presence of carbidic (atomic) carbon ${ }^{17,18}$ indicating extensive $\mathrm{C}-\mathrm{H}$ bond scission by $500 \mathrm{~K}$. This notion is corroborated by the fact that $\mathrm{H}_{2}$ desorption diminishes at this temperature (Figure 3c).

An additional reaction pathway, also found on $\mathrm{Ni}(110),{ }^{38}$ is iodomethane formation (Figures $3 \mathrm{~b}$ and $6 \mathrm{~b}$ ). Iodomethane only 


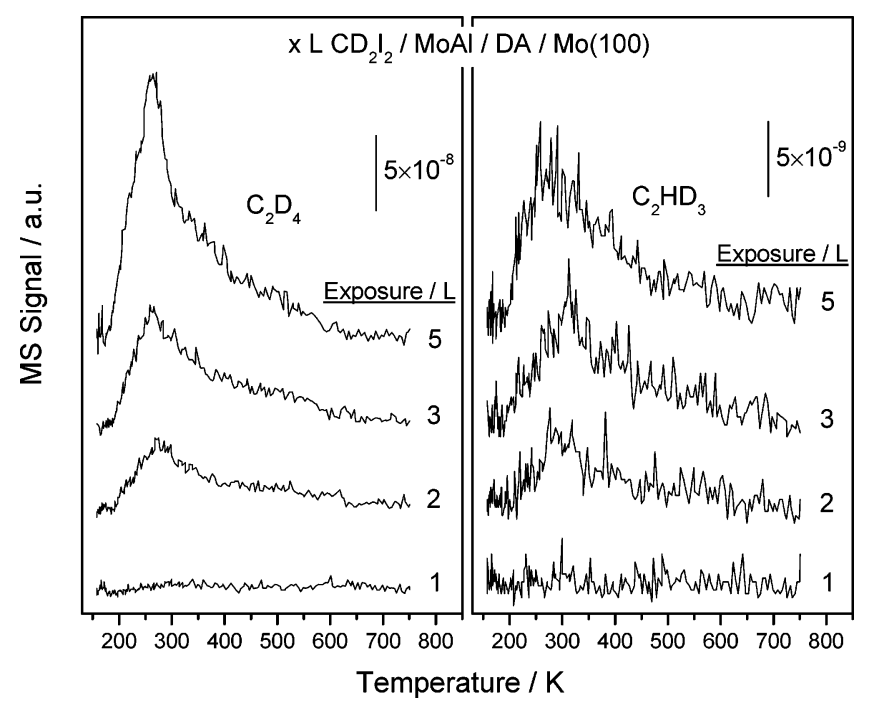

Figure 8. $32\left(\mathrm{C}_{2} \mathrm{D}_{4}\right)$ and $31\left(\mathrm{C}_{2} \mathrm{HD}_{3}\right)$ amu temperature-programmed desorption spectra of $\mathrm{CD}_{2} \mathrm{I}_{2}$ adsorbed on MoAl film at $150 \mathrm{~K}$ collected using a heating rate of $10 \mathrm{~K} / \mathrm{s}$, as a function of $\mathrm{CD}_{2} \mathrm{I}_{2}$ exposure.

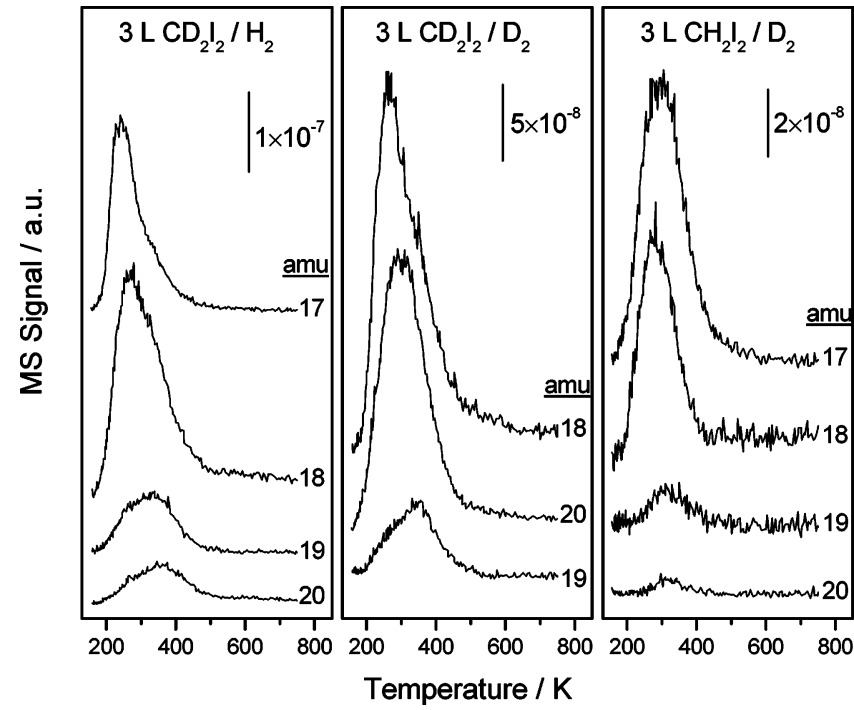

Figure 9. $17\left(\mathrm{CH}_{3} \mathrm{D}\right), 18\left(\mathrm{CH}_{2} \mathrm{D}_{2}\right), 19\left(\mathrm{CHD}_{3}\right)$, and $20\left(\mathrm{CD}_{4}\right)$ amu temperature-programmed desorption spectra following $3 \quad \mathrm{~L}^{-\mathrm{CD}_{2} \mathrm{I}_{2}}$ $\left(\mathrm{CH}_{2} \mathrm{I}_{2}\right)$ adsorption on a $\mathrm{H}_{2}\left(\mathrm{D}_{2}\right)$ presaturated $\mathrm{MoAl}$ surface.

\section{SCHEME 1}
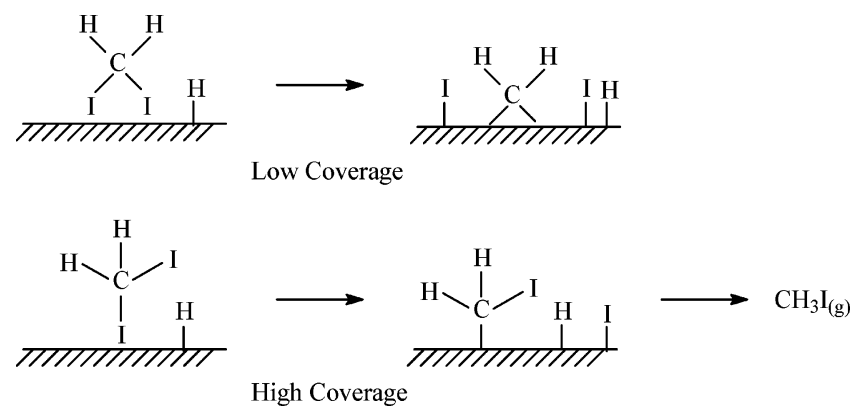

forms following diiodomethane saturation. Since iodomethane can only be formed through a $\mathrm{CH}_{2} \mathrm{I}-\left(\mathrm{CD}_{2} \mathrm{I}-\right)$ intermediate, it is expected that, at low diiodomethane coverages, this intermediate is not formed. However, at high coverages, diiodomethane may adopt a geometry such that one $\mathrm{C}-\mathrm{I}$ bond is oriented away from the surface because of surface crowding, thus protecting it from further dissociation as in Scheme 1.
4.2. Formation of Methane and Higher Hydrocarbons. Methane is formed through a stepwise hydrogenation of surface methylene species as indicated by data shown in Figure $7 \mathrm{~b}$ where, in this case, hydrogen originating from the background incorporates into the desorbing $\mathrm{CH}_{2} \mathrm{D}_{2}$ and $\mathrm{CHD}_{3}$. It is found that $\mathrm{H}$ reacts with methylene species more easily than deuterium (Figures $7 \mathrm{~b}$ and 9). This effect has been noted previously ${ }^{38}$ and has been ascribed to a large normal kinetic isotope effect, which favors the incorporation of $\mathrm{H}$ compared to $\mathrm{D}$. Methane formation commences at $\sim 200 \mathrm{~K}$ with a desorption maximum at $\sim 350$ $\mathrm{K}$, in case the surface is not precovered with hydrogen (Figure $3 \mathrm{~d}$ ). In the presence of preadsorbed hydrogen, methane desorption still commences at $\sim 200 \mathrm{~K}$ but with a lower desorption maximum (Figure 9). The methane yield is also much higher on hydrogen-precovered surfaces. These data taken together demonstrate that methane formation is limited by the availability of surface hydrogen.

It has been found previously that methane is formed from methyl iodide at temperatures that are almost identical to those found here, both on clean and hydrogen-precovered surfaces. ${ }^{23}$ This strongly suggests that methyl formation is a facile process, while methyl hydrogenation is the rate-limiting step. Interestingly, it is also found that, when deuterium adatoms are available, either by adsorbing $\mathrm{D}_{2}$ on the surface or by cracking $\mathrm{CD}_{2} \mathrm{I}_{2}$, all deuterium-substituted methanes from $\mathrm{CH}_{3} \mathrm{D}$ to $\mathrm{CD}_{4}$, are formed (Figure 9). This suggests that, although the first step of methylene hydrogenation, that is, methyl formation, is a favored process, the reverse process is not completely blocked.

Higher hydrocarbons are formed on the surface including ethylene, ethane, propylene, and butene (Figures 4 and 8). Ethylene could be formed by two routes: either methylene coupling or methylene insertion into metal-methyl bond followed by $\beta$-hydride elimination. Although methylene coupling occurs in most cases, ${ }^{22}$ it appears not to be the dominating mechanism on the MoAl alloy. First, and perhaps the most convincing evidence, is that a significant amount of $\mathrm{C}_{2} \mathrm{HD}_{3}$ desorbs at approximately the same temperature as $\mathrm{C}_{2} \mathrm{D}_{4}$ during thermal activation of adsorbed $\mathrm{CD}_{2} \mathrm{I}_{2}$ (Figure 8). Second, being a product from a second-order reaction coupling, the ethylene desorption temperature should decrease with increasing diiodomethane exposures as observed previously, ${ }^{44}$ and this is not seen (Figures 4 and 8). This argument depends on the rate of ethylene formation being reaction-rate limited. It is found, however, that molecular ethylene desorbs from the alloy surface at substantially lower temperatures. ${ }^{45}$

It is also proposed that both ethylene and ethane are formed by the same route as propylene and butene; that is, the reaction is initiated by the insertion of methylene species into metalmethyl bond to form a metal-ethyl intermediate. This can undergo $\beta$-hydride elimination to form ethylene or hydrogenation to yield ethane. Additional methylenes can insert into the ethyl species to form longer alkyl groups that also undergo $\beta$-hydride elimination reactions to produce $\mathrm{C}_{3}$ and $\mathrm{C}_{4}$ olefins. Except at a $\mathrm{CH}_{2} \mathrm{I}_{2}$ exposure of $1 \mathrm{~L}$ where the ethane desorption temperature is slightly lower than ethylene, at exposures of 3 and $5 \mathrm{~L}$, the desorption temperatures of these two molecules are identical (Figure 4). This suggests that methylene insertion is the rate-limiting step while $\beta$-hydride and reductive elimination reactions are fast. The desorption temperatures of propylene and butene, on the other hand, are $\sim 30 \mathrm{~K}$ higher than ethylene and ethane. This indicates that higher hydrocarbon formation is limited by the availability of surface methylene species. A typical characteristic for oligomerization by such a methylene insertion mechanism is an exponential decrease of the yield with 


\section{SCHEME 2}

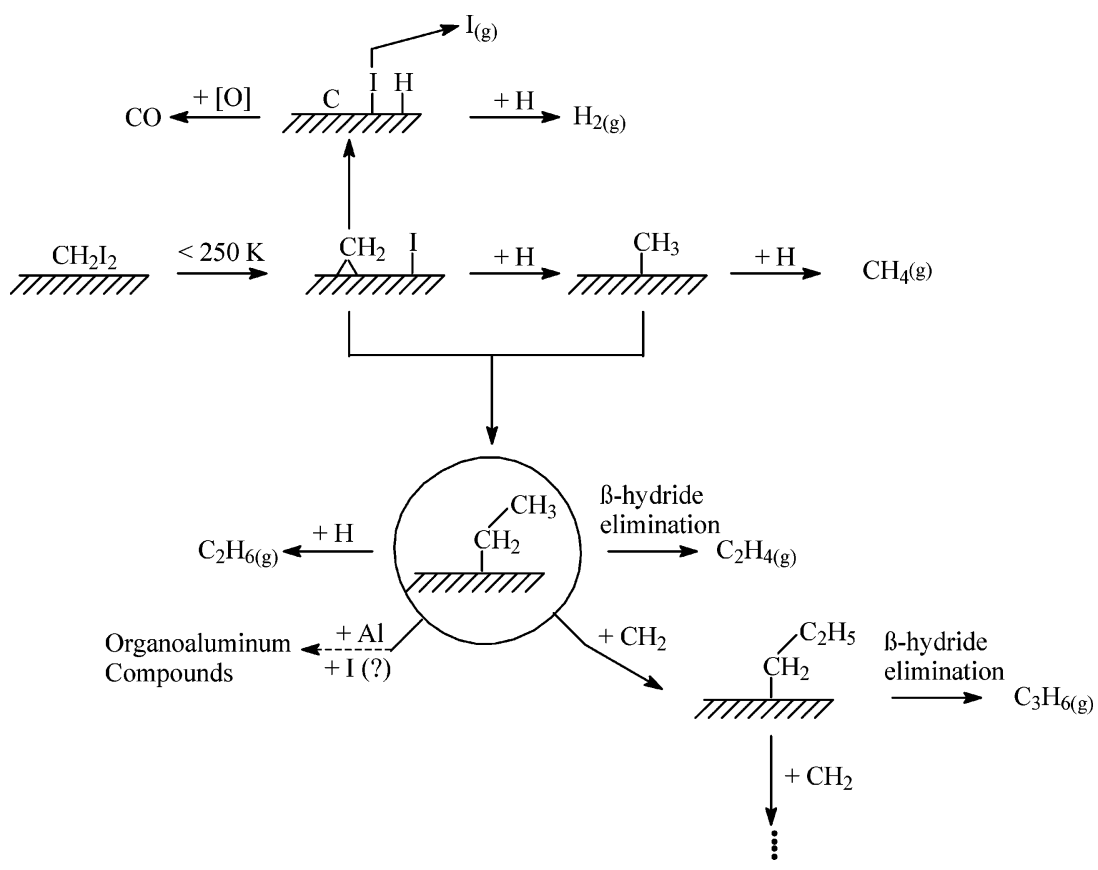

increasing chain length (with a Schulz-Flory distribution). ${ }^{46}$ This behavior is shown clearly in Figure 4. The origin of the small amount of ethane that desorbs at $\sim 210 \mathrm{~K}$ following 3 and $5 \mathrm{~L} \mathrm{CH}_{2} \mathrm{I}_{2}$ exposures (Figure 4) is not very clear. Presumably, this is due to methyl coupling considering the facile methyl formation process and the fact that this state increases with increasing $\mathrm{CH}_{2} \mathrm{I}_{2}$ exposure, although hydrogenation of the ethyl group cannot be excluded.

4.3. High-Temperature Desorption Products. Hydrogen and the majority of the hydrocarbons desorb at below $500 \mathrm{~K}$. However, detectable desorptions at amu 26, 27, and 30 (Figure 4) and amu 31 and 32 (Figure 8) are found between 500 and $600 \mathrm{~K}$. Although such high-temperature desorption states have not been observed on Mo surfaces, ${ }^{29,30}$ organoaluminum desorption is found at these temperatures on aluminum, ${ }^{40}$ and the desorption intensity at higher temperatures is assigned to organoaluminum formation. Since this reaction channel is rather minor, it is not possible to discuss these reaction pathways in greater detail.

Iodine desorbs from the surface between 700 and $1100 \mathrm{~K}$ (Figure 5b). Iodine desorbs atomically from most transitionmetal surfaces at such high temperatures. ${ }^{21,22} \mathrm{CO}$ desorbs from the surface at $1100 \mathrm{~K}$ and above with a desorption maximum at $\sim 1200 \mathrm{~K}$ (Figure 5a), because of reaction between the alumina substrate and carbidic carbon originating from diiodomethane dissociation, and this reaction pathway has been confirmed previously by isotope $\left({ }^{18} \mathrm{O}\right)$ labeling TPD experiments. ${ }^{18}$ The $\mathrm{CO}$ desorption yield decreases at high $\mathrm{CH}_{2} \mathrm{I}_{2}$ exposures (inset, Figure 5a), suggesting that iodine adsorption blocks a portion of surface sites where methylene species decompose.

Assuming that the high-temperature $\mathrm{CO}$ desorption state removes all carbon originating from complete $\mathrm{CH}_{2} \mathrm{I}_{2}$ dissociation ( $\mathrm{CO}_{2}$ desorption is also observed at $\sim 1000 \mathrm{~K}$, but the intensity is negligible compared to $\mathrm{CO}$ ), the percentage of adsorbed methylene species that converts into gaseous products can be estimated where, at a $\mathrm{CH}_{2} \mathrm{I}_{2}$ exposure of $5 \mathrm{~L}, \sim 90 \%$ of the adsorbed methylene species dissociate completely to hydrogen and carbon. For the remaining $\sim 10 \%$ that converts into gaseous products, higher hydrocarbons comprise $\sim 40 \%$. The overall reaction mechanism, following the above discussion, is summarized in Scheme 2.

4.4. Comparison with the Chemistry on Other Surfaces. The thermal chemistry of diiodomethane has been extensively studied on various metal surfaces ${ }^{21,22}$ and in most cases, methylene coupling to form ethylene, decomposition to carbon and hydrogen, and hydrogenation to methane are the major reaction pathways. As has been shown above, methylene insertion reaction requires the coexistence of both alkyl and methylene species on the surface. This is rather difficult since the insertion reaction competes with many other reactions including coupling, hydrogenation, and dehydrogenation. It is therefore not surprising that similar chemistry has only been found for $\mathrm{Ni}(110) .{ }^{38}$ In that case, $\sim 10 \%$ of the adsorbed methylene species converts to higher hydrocarbons up to butene.

On coinage metal surfaces, ethylene appears to be the only hydrocarbon formed from diiodomethane, in these cases, through methylene coupling. Methylene insertion does not occur since methyl species are not formed. ${ }^{25}$ This reaction channel can be activated, however, when iodomethane and diiodomethane are coadsorbed on the surface..$^{25,47-49}$ On molybdenum, ${ }^{29,30}$ methane is the only hydrocarbon product. Lack of $\mathrm{CHD}_{3}$ and $\mathrm{CD}_{4}$ desorption when the surface is predosed with $\mathrm{D}_{2}$ suggests that the coexistence of considerable amounts of methyl and methylene species is not achieved. Aluminum has been found to catalyze methylene coupling reaction at rather low temperatures. However, methylene insertion reactions are not found. ${ }^{39-41}$

The unique reactivity of the MoAl for higher hydrocarbon formation may be due to two effects, either electronic or geometric. In the first effect, molybdenum will gain electrons by alloying with aluminum causing larger d-band occupancy, so that it becomes electronically more like a noble metal. Second, it could also be due to the blocking of reactive sites on the surface by coordination to aluminum and the resulting iodine, which inhibits both the deep hydrogenation of the resulting surface methyl species and the deep dehydrogenation of methylene species, allowing the latter to have sufficient time to insert into an alkyl-surface bond. 


\section{Conclusions}

Diiodomethane reacts to form methylene species and adsorbed iodine below $\sim 250 \mathrm{~K}$ on a $\mathrm{MoAl}$ alloy formed from $\mathrm{Mo}(\mathrm{CO})_{6}$ on dehydroxylated alumina. Approximately $90 \%$ of the adsorbed methylene species decomposes to deposit carbon and evolve hydrogen. A portion of the reactively formed methylene species hydrogenate to methyl species. These can either hydrogenate further to form methane or undergo sequential methylene insertion reactions to form alkyl species. These can react by $\beta$-hydride elimination to form alkenes up to $\mathrm{C}_{4}$. Some ethane formation is also found, which is formed by either methyl coupling or by hydrogenation of the ethyl species.

Acknowledgment. We gratefully acknowledge support of this work by the Chemistry Division of the National Science Foundation under grant number CTS-0105329.

\section{References and Notes}

(1) Brenner, A. J. Mol. Catal. 1979, 5, 157.

(2) Davie, E.; Whan, D. A.; Kemball, C. J. Catal. 1972, 24, 272.

(3) Smith, J.; Howe, R. F.; Whan, D. A. J. Catal. 1974, 34, 191.

(4) Thomas, R.; Moulijn, J. A. J. Mol. Catal. 1982, 15, 157.

(5) Brenner, A.; Burwell, R. L., Jr. J. Am. Chem. Soc. 1975, 97, 2565.

(6) Brenner, A.; Burwell, R. L., Jr. J. Catal. 1978, 52, 353.

(7) Howe, R. F. Inorg. Chem. 1976, 15, 486.

(8) Kazusaka, A.; Howe, R. F. J. Mol. Catal. 1980, 9, 183

(9) Reddy, K. P.; Brown, T. L. J. Am. Chem. Soc. 1995, 117, 2845. 102.

(10) Zecchina, A.; Platero, E. E.; Areán, C. O. Inorg. Chem. 1988, 27,

(11) Howe, R. F.; Leith, I. R. J. Chem. Soc., Faraday Trans. 1 1973, 69, 1967.

(12) Shirley, W. M.; McGarvey, B. R.; Maiti, B.; Brenner, A.; Cichowlas, A. J. Mol. Catal. 1985, 29, 259.

(13) Kaltchev, M.; Tysoe, W. T. J. Catal. 2000, 193, 29.

(14) Kaltchev, M.; Tysoe, W. T. J. Catal. 2000, 196, 40.

(15) Wang, Y.; Gao, F.; Kaltchev, M.; Stacchiola, D.; Tysoe, W. T. Catal. Lett. 2003, 91, 88.

(16) Wang, Y.; Gao, F.; Kaltchev, M.; Tysoe, W. T. J. Mol. Catal. A: Chem. 2004, 209, 135.
(17) Wang, Y.; Gao, F.; Tysoe, W. T. J. Mol. Catal. A: Chem. 2005, $226,18$.

(18) Wang, Y.; Gao, F.; Tysoe, W. T. J. Mol. Catal. A: Chem. 2005, $225,173$.

(19) Hwu, H. H.; Zellner, M. B.; Chen, J. G. J. Catal. 2005, 229, 35.

(20) Wang, Y.; Gao, F.; Tysoe, W. T. in preparation.

(21) Zaera, F. Chem. Rev. 1995, 95, 2651

(22) Bent, B. E. Chem. Rev. 1996, 96, 1361.

(23) Wang, Y.; Gao, F.; Tysoe, W. T. Surf. Sci., in press.

(24) Chiang, C. M.; Wentzlaff, T. H.; Jenks, C. J.; Bent, B. E. J. Vac. Sci. Technol., A 1992, 10, 2185.

(25) Liu, J. L.; Chiang, C. M.; Jenks, C. J.; Yang, M. X.; Wentzlaff, T. H.; Bent, B. E. J. Catal. 1994, 147, 250.

(26) Domen, K.; Chuang, T. J. J. Chem. Phys. 1989, 90, 3332.

(27) Domen, K.; Chuang, T. J. Phys. Rev. Lett. 1987, 59, 1484.

(28) Wu, G.; Stacchiola, D.; Collins, M.; Tysoe, W. T. Surf. Rev. Lett. 2001, 8, 303

(29) Weldon, M. K.; Friend, C. M. Surf. Sci. 1994, 321, L202.

(30) Wu, G.; Bartlett, B. F.; Tysoe, W. T. Surf. Sci. 1997, 373, 129.

(31) Solymosi, F.; Kovacs, I. Surf. Sci. 1993, 296, 171.

(32) Kovacs, I.; Revesz, K.; Solymosi, F. Catal. Lett. 1994, 27, 53.

(33) Zaera, F.; Hoffmann, H. J. Phys. Chem. 1991, 95, 6297.

(34) Klivenyi, G.; Solymosi, F. Surf. Sci. 1995, 342, 168.

(35) Bol, C. W. J.; Friend, C. M. J. Am. Chem. Soc. 1995, 117, 11572.

(36) Kis, A.; Smith, K. C.; Kiss, J.; Solymosi, F. Surf. Sci. 2000, 460, 190.

(37) Tjandra, S.; Zaera, F. J. Catal. 1993, 144, 361.

(38) Guo, H.; Zaera, F. Surf. Sci. 2003, 547, 284.

(39) Domen, K.; Chuang, T. J. J. Am. Chem. Soc. 1987, 109, 5288.

(40) Hara, M.; Domen, K.; Kato, M.; Onishi, T.; Nozoye, H. J. Phys. Chem. 1992, 96, 2637.

(41) Kondo, J. N.; Higashi, T.; Yamamoto, H.; Hara, M.; Domen, K.; Onishi, T. Surf. Sci. 1996, 349, 294.

(42) Wytenburg, W. J.; Lambert, R. M. J. Vac. Sci. Technol., A 1992, $10,3597$.

(43) Briggs, D.; Seah, M. P. Practical Surface Analysis: Auger and $X$-ray Photoelectron Spectroscopy; John Wiley \& Son, 2004.

(44) Kovacs, I.; Solymosi, F. J. Phys. Chem. B 1997, 101, 5397.

(45) Wang, Y.; Gao, F.; Tysoe, W. T. in preparation.

(46) Vannice, M. A. Catal. Rev. Sci. Eng. 1976, 14, 153.

(47) Wu, H.-J.; Chiang, C.-M. J. Phys. Chem. B 1998, 102, 7075.

(48) Wu, H.-J.; Hsu, H.-K.; Chiang, C.-M. J. Am. Chem. Soc. 1999, $121,4433$.

(49) Huang, W.; White, J. M. J. Am. Chem. Soc. 2004, 126, 14527. 